\title{
First record of gynandromorphy in fossil Chironomidae (Diptera) from Late Eocene Rovno amber
}

\author{
Viktor Baranov ${ }^{1}$, Evgeny Perkovsky ${ }^{2}$ \\ ${ }^{1}$ Leibniz Institute of Freshwater Ecology and Inland Fisheries, Berlin, Germany. \\ E-mail: baranov@igb-berlin.de \\ 2I.I. Schmalhausen Institute of Zoology NASU, Kiev, Ukraine.E-mail: perkovsk@gmail.com
}

Gynandromorphy as an abnormal mixture of sex-specific traits of males and females in an individual is wide spread among the Chironomidae (Martin and Lee 2000). Gynandromorphy could be caused by mutation in the mitosis regulating genes, which creates an abnormal puzzle of "genetically masculine" and "feminine" body parts, or by other factors like Mermithidae (Nematoda) parasites (Martin 1994). Gynandromorphs can be categorized based on morphology and relationships between "male" and " female" parts of the body. Basically they could be divided in 3 groups: a) anteroposterior gynandromorphs - with anterior and posterior parts of the body possessing traits of different sexes; b) lateral - with body possessing different sexes traits on the left and right sides; c) mosaic - with sexual traits creating a sophisticated puzzle where wings and limbs can be attributed to the phenotypes of different sexes (Martin 1994, Rempel 1940). Studies of gynandromorphs are important for understanding Chironomidae sex determination mechanisms and evolution of the group.

Up to now, gynandromorphs have been recorded only in recent Chironomidae. Herein we present the first fossil record of Chironomidae gynandromorphy based on an inclusion in the Late Eocene Rovno amber from Ukraine.

Late Eocene Rovno amber represents a southern coeval analogue of Baltic amber (Baranov et al. 2014). Chironomids are diverse and abundant in Rovno amber, with up to 15 genera from 4 subfamiles recorded from that deposit, three of these genera being known only from Rovno amber (Baranov et al. 2014; Giłka et al. 2013, Zelentsov et al. 2012). The gynandromorph was found during a survey of the I.I. Schmalhausen Institute of Zoology collection of nematoceran Diptera in amber.

\section{Materials and methods}

Rovno amber belongs to the succinites, as does the well-known Baltic amber (Zelentsov et al. 2012). The piece of amber containing the gynandromorphic midge was found in Klesov (Pugach quarry) and obtained from "Ukramber" factory (Rovno). The specimen is moderately well preserved (Fig. 1). However, the wings are folded and thus difficult to examine, and the hypopygium is unavailable for examination, because of an air bubble. The specimen was examined using standard techniques (Baranov et al. 2014). The general terminology follows Sæther (1980). The voucher specimen is housed at the I. I. Schmalhausen Institute of Zoology, National Academy of Science of Ukraine, Kiev (SIZK), Ukraine under catalogue number K-5404.

Photographs were taken at the Paleontological Institute, Russian Academy of Sciences (PIN PAS) in Moscow by Victor Kolyada using a Leica M 165 microscope and Leica DFC 425 camera.

\section{Description}

The specimen is attributed to the subfamily Orthocladiinae (Diptera, Chironomidae) based on the combination of the observable part of the wing, structure, shape of flagellomeres, legs, and especially tibial combs structure (Fig.1A). Further identification is impossible, due to unavailable details of wings and genitalia. At the left side of scutum a large triangular wound can be seen (Fig. 1A). It could be a marking from an insectivorous biting midge (Diptera, Ceratopogonidae) attack. It has been shown that insectivorous biting midges, like Eohelea sinuosa (Meunier, 1904), frequently attacked chironomids in the Rovno amber forest (Perkovsky 2013; Perkovsky and Rasnitsyn 2013).

Wing length is about $800 \mu \mathrm{m}$. Body length is $835 \mu \mathrm{m}$. The specimen possesses evident lateral gynandromorphy, as can be seen from the antennae structure. The left antenna is typically male, with 10 flagellomeres and long bristles. $\mathrm{AR}=0,74$. In contrast, the right antenna is of typically female structure, consisting of only five flagellomeres and with no long bristles. The pedicellus of the left antenna is much smaller than the right one (Fig. 1B). No signs of mermithids (Nematoda, Mermithidae) or other parasitic worms, have been found on the midge body. 


\section{Discussion}

Amber as a fossil container for exceptionally well preserved organisms plays an important role in our understanding of evolution. By studying amber we are gaining more than just a list of new taxa. Often we are able to reconstruct sophisticated connections in the environment of the distant past. Much work has been done on parasitism, mutualistic connection, predation, sexual selection etc. based on amber fossils (Azar 2007). The record of the chironomid gynandromorphy allows as to assume that the sex-determination system of the Chironomidae 40 million years old could have been similar to that of the present (Martin and Lee 2000), because of the similar "typeset errors" like lateral gynandromorphy. We could claim that in this particular case the abnormality was genetically determined, because we have found no signs of Mermithidae or other parasites which could cause such abnormality (Yakovlev pers. comm. 2014). This record once again has proved the importance of amber paleontology for the research in Chironomidae systematics and evolution.

\section{Acknowledgments}

The authors express their sincere gratitude to Egor Yakovlev (I.I. Schmalhausen Institute of Zoology NAS of Ukraine, Kiev) for his invaluable help with parasitological examination of the specimen and valuable comments on Insecta-Nematoda interactions as cause for gynandromorphy. To Viktor Kolyada (Moscow) for kindly taking photo-
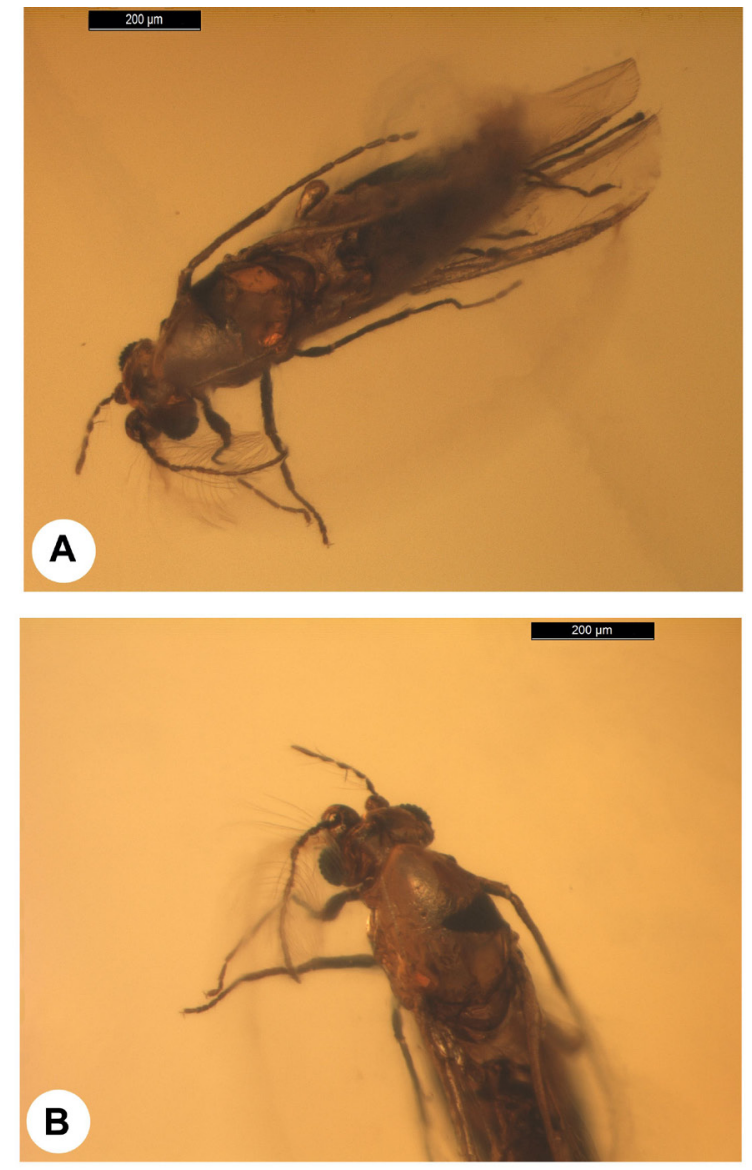

Figure 1. A: Orthocladiinae gynandromorph in amber (K5404) - total view. B: Orthocladiinae gynandromorph in amber (K-5404) - head and thorax. graphs of the specimen and Alexandr Rasnitsyn (Moscow) for constant help and support.

\section{References}

Azar, D. 2007. Preservation and accumulation of biological inclusions in Lebanese amber and their significance. - Comptes Rendus Palevol 6(1): 151-156.

Baranov, V., Andersen, T. and Perkovsky, E. 2014. A new genus of Podonominae (Diptera: Chironomidae) in Late Eocene Rovno amber from Ukraine. - Zootaxa 3794(4): 581-586.

Giłka, W., Zakrzewska, M., Dominiak, P. and Urbanek, A. 2013. Non-biting midges of the tribe Tanytarsini in Eocene amber from the Rovno region (Ukraine): a pioneer systematic study with notes on the phylogeny (Diptera: Chironomidae). - Zootaxa 3736(5): 569-586.

Martin, J. 1994. A mutation of Chironomus tentans Fab. that leads to gynandromorph and mosaic formation. Pp. 55-60. In: Chironomids: from genes to ecosystems, P. Cranston (ed.) East Melbourne ,CSIRO Publications, Melbourne, Australia, 482 pp.

Martin, J. and Lee, B.T.O. 2000. Sex determination in Chironomus and the Drosophila paradigm. pp. 177181, In: Late 20th Century Research on Chironomidae. O. Hoffrichter (ed.) Shaker Verlag, Aachen, Germany. $661 \mathrm{pp}$.

Perkovsky, E. E. 2013. Eohelea sinuosa (Meunier, 1904) (Diptera, Ceratopogonidae) in Late Eocene ambers of Europe. - Paleontological Journal 47(5): 503-512.

Perkovsky E.E. and Rasnitsyn A.P. 2013. Biting midges (Diptera, Ceratopogonidae) in amber forest communities based on analysis of syninclusions in Late Eocene Rovno amber. - Terrestrial Arthropod Reviews 6 (1-2): 71-80. 
Rempel, J. G. 1940. Intersexuality in Chironomidae induced by nematode parasitism. - Journal of Experimental Zoology 84(2): 261-289.

Sæther O.A. 1980. Glossary of chironomid morphology terminology (Chironomidae, Diptera). - Entomologica scandinavica, Supplement 14: 1-51.

Zelentsov, N. I., Baranov, V. A., Perkovsky, E. E. and Shobanov, N. A. 2012. First records on non-biting midges (Diptera: Chironomidae) from the Rovno amber. - Russian Entomological Journal 21: 79-87. 